\title{
A CALIBRATION TEST OF KARST COLLAPSE MONITORING DEVICE BY OPTICAL TIME DOMAIN REFLECTOMETRY(BOTDR) TECHNIQUE
}

\author{
Guan Zhende, Jiang Xiaozhen, Gao Ming \\ Institute of Karst Geology, CAGS, Qixing 50 Rd., Guilin, GuangXi 130026 P.R. China, guanzd@karst.ac.cn
}

\begin{abstract}
Brillouin Optical Time Domain Reflectometry (BOTDR) is a distributed fiber optic strain sensing systems based on Brillouin scattering. This technique may potentially become a useful tool to monitor and predict karst collapse, especially for linear infrastructure such as roads, highways, and railways. This paper introduces a calibration device which is used to establish the relationship between fiber deformation and underlain soil -cave dimension. Based on the deformation characteristics of the sinkhole collapse, the mechanical relation between soil body and sensing fiber is analyzed, and a simplified model of collapse is proposed for testing design. The experimental tests are carried out through the designed equipment to investigate the effect of the sinkhole's size and the overburden stratum's thickness on embedded optical fibers. Firstly, the sinkhole formation process was stimulated with the orderly changes in load on the optical fiber. Secondly, the impact of the changes of sinkhole size on the sensing fiber monitoring was analyzed. It shows from the experiment results that the strain change in the sinkhole formation process can be monitored by distributed optical fiber sensing technology and the sinkhole size can be reflected through the optical fiber strain range. Besides, the sensibility of coated optical fiber in sinkhole collapse monitoring tests varies between different types of optical fibers. Due to the effective response of the distributed optical fiber sensing technology to sinkhole forming and evolving, it can be adopted in the monitoring for potential sinkhole collapse.
\end{abstract}

\section{Preface}

Karst is widely distributed in Southwest China . Along with the large-scale development and rapidly increasing of human activities, geological disasters related to karst have become prominent, especially karst collapse (sinkhole collapse), which has become the major geological problems of highways, high-speed railways, oil \& gas pipelines and other projects in karst region
(Chen, no date). How to avoid karst collapse, specially its potential threat to existing projects, has become a significant challenge for engineering geologists.

The most effective means to avoid geological disasters is prevention. Therefore, monitoring and early warning of karst collapse are particularly important. Current monitoring methods for karst collapse includes Ground Penetrating Radar (GPR) survey, Time Domain Reflectometry (TDR) technique and monitoring of the water or air pressure changes in underground karst system. Periodical GPR survey may find potential collapse abnormalities, but due to its strict working environment, limited detection depth, professional operation and high cost, it has limitations for long-term monitoring. TDR technique has many advantages, such as mature technology, distributed monitoring, antiinterference and comparatively low price. However, TDR cannot be used to monitor the formation process of karst collapse because it receives only the signal from the monitoring object which is effected by shearing force, tension or both combined. Monitoring water and air pressure changes in underground karst system can only forecast the collapse risk of the karst fracture around the monitoring points. But it cannot point out the specific location where karst collapse may occur. Therefore, traditional monitoring methods cannot meet the demand for sinkhole collapses monitoring or forecast, which usually occurs abruptly and indefinitely. Brillouin Optical Time Domain Reflectometry (BOTDR) is a distributed fiber optic strain sensing system, which can detect temporal and spatial changes of external physical parameters at large-scales and on a continuous basis (Tang et al., 2006). Nevertheless, there are still many problems in the application (Jiang et al., 2006; Li et al., 2005; Meng et al., 2011). According to the deformation characteristics obtained from sinkhole collapse modeling and calibration testing, we analyzed the mechanic relation between the soil and sensing fiber, and studied the application of distributed optical 
fiber sensing technology as a predictor of potential sinkhole collapse.

\section{Monitoring principle of optical fiber sensing technology}

The distributed optical fiber sensing technology is based on three spectroscopic analysis methods including Rayleigh scattering, Brillouin scattering and Raman scattering. Rayleigh scattering is an elastic scattering which does not cause frequency drift in the optical fiber. Brillouin and Raman scattering are nonelastic scattering which may cause frequency drift in the optical fiber (Yu, 2006). Brillouin scattering arises from the interaction between optical and acoustic waves propagating in the optical fiber (Figure 1). The relationship between Brillouin scattering frequency and the temperature or strain of the optical fiber is linear. So, the changes in temperature or axial strain can be calculated according to the amount of the frequency drift in the optical fiber. In order to obtain the drift of the axial strain only, one optical fiber sensor without external force or a temperature sensor is adopted to offset the drift by temperature change.

The relationship between the center frequency drift and axial strain in optical fiber

$$
V_{B}(\varepsilon)=V_{B}(0)+\frac{\partial V_{B}(\varepsilon)}{\partial \varepsilon} \varepsilon
$$

where:

$\operatorname{VB}(\varepsilon)$ - Brillouin scattering frequency of axial stretched optical fiber;

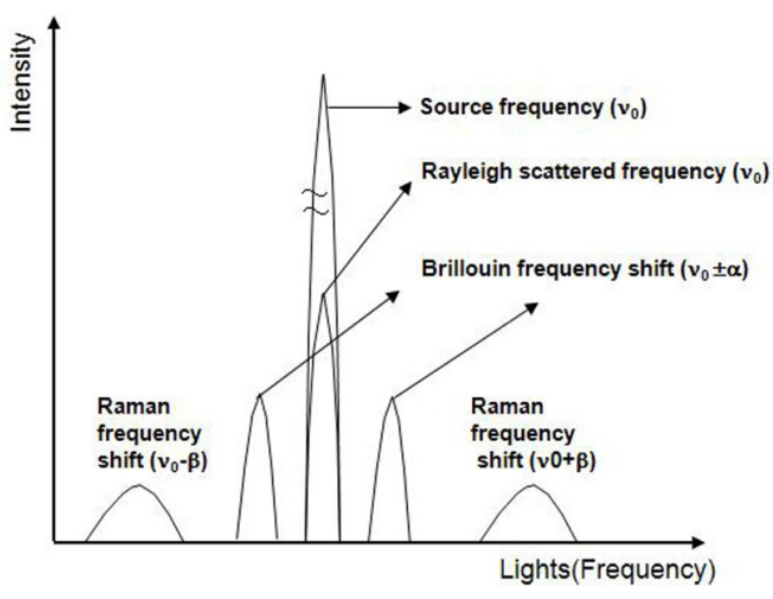

Figure 1. The principle of BOTDR.
$\mathrm{VB}(0)$ - Brillouin scattering center frequency of no stress optical fiber;

$\partial V_{B}(\varepsilon) / \partial \varepsilon$-strain coefficient;

$\varepsilon$ - optical fiber axial strain.

The strain coefficient usually is $0.5 \mathrm{GHz} / \%$, which is decided by the material properties of the optical fiber. The optical fiber strain is about $0.0493 \mathrm{MHz} / \mu \varepsilon$ (Liu et al., 2006) when the incident pulse wavelength is $1.55 \mu \mathrm{m}$. The center frequency drift is influenced by the temperature changes. The experimental temperature variation is less than $5^{\circ} \mathrm{C}$, so the temperature effects were not considered.

BOTDR is a distributed fiber optical strain sensing technology based on Time Domain Reflectometer (OTDR) technique. According to the OTDR principle, the scattering position can be determined by measuring the scattered laser echo time. The distance between the pulse laser injection point and any point in the optical fiber can be counted by the following equation.

$$
\mathrm{Z}=\mathrm{cT} /(2 \mathrm{n})
$$

where:
Z-distance;
c- light velocity in vacuum;
n- refractive index of optical fiber;

T-time difference between sending and receiving a pulse laser.

According to Equation (1), the axial strain distribution of the optical fiber can be calculated (Zhang et al., 2003; Shi et al., 2005). According to Equation (2), the position where strain occurred can be calculated.

\section{The karst collapse monitoring model}

The working principle of BOTDR for collapse monitoring is based on the development of a karst soil void that manifests as deformation of the overburden time until a cover-collapse sinkhole forms at the surface. So, a sensing fiber can be buried where collapse may probably occur and the fiber deforms under the load coming from overlying stratum due to the development of a soil void. The location, scale and development of soil void can be well understood based on the analysis of temporal and spatial variation of sensing fiber strain. 


\section{Deformation compatibility of fiber and soil}

The formation of soil void is the result of varied superimposing collapse factors, which causes overlying soil deformation or potential collapse. The key to the BOTDR monitoring is the accurate finding of such deformation. Reasonable distribution of the sensing fiber to keep synchronal deformation with the soil mass is important during soil void monitoring. The placement of the sensing fiber is determined by the distribution features of karst collapse in the monitoring region. In our research, the model was simplified so that the sensing fiber goes through the center of the soil void overburden stratum. During the development of collapse, deformation of the soil mass occurs gradually, and also the fiber buried there is stretched downward with sliding deformation called compatible deformation.

Compatible deformation of fiber and soil is not only related to the fiber material and its structure, but also is influenced by the interaction between soil and fiber. And this interaction will be explained by mechanical analysis in the following discuss.

Referring to mechanical relationship between fiber and soil as Figure 2 shows, the fiber internal force variation (dT) can be demonstrated as below:

$$
\mathrm{dT}=(\pi \mathrm{D}) \tau \mathrm{dx}=\left(1 / 4 \pi \mathrm{D}^{2}\right) . \mathrm{E} \cdot \mathrm{d} \varepsilon
$$

where:

E-elastic modulus of fiber;

T-shear stress on the fiber surface;

D- diameter of the fiber;

$\mathrm{d} \varepsilon$-gradient of strain variation;

$\mathrm{dx}$-differential length along fiber axial direction

Thus (Li et al.):

$$
\mathrm{c}=\frac{\mathrm{DE}}{4} \frac{\mathrm{d} \mathrm{s}}{\mathrm{dx}}
$$

Shear stress exiting on fiber surface is produced by the friction between soil and fiber cover. Sliding friction is smaller than maximum static friction, so sliding friction is taken in the analysis.

$$
\tau=-f=-\mu \mathrm{N}=-\mu \text {.G土 }=-\mu \gamma \mathrm{h}
$$

where: f- friction between soil and fiber cover;

$\mu$ - coefficient of friction;

$\mathrm{N}$ - vertical pressure imposed on fiber by overburden soil;

G土- weight of incumbent soil;

$\gamma$ - equivalent bulk density of incumbent soil;

$\mathrm{h}$ - thickness of incumbent soil.

According to Equations (4) and (5):

$$
\mathrm{d} \varepsilon=-\frac{4 \mu \gamma \mathrm{h}}{\mathrm{DE}} \mathrm{dx}
$$

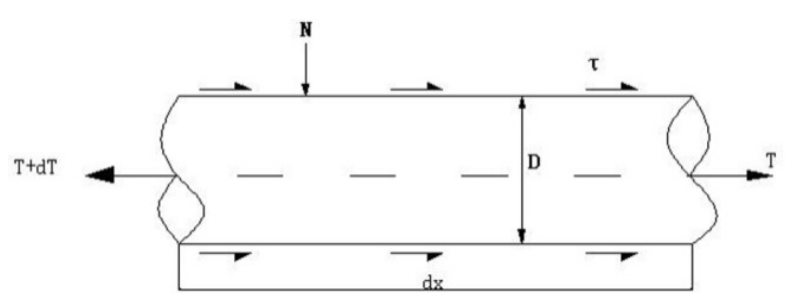

Figure2. The mechanic relationship between soil and optical fiber.

As explained in the theory mentioned above, when relative displacement occurs between fiber and soil under the condition of invariable fiber material, constant soil thickness and bulk density, stress is directly proportional to the coefficient of friction. Force transmission of sensing fiber buried in the soil mass relies on the friction between fiber cover and soil. Thus, fiber deformation happens while soil is deformed.

\section{Simplification of collapse monitoring model}

As soil void develops, incumbent soil load and void scale are critical to the magnitude and distribution of the stress around the developing void. According to the key monitoring factors and the deformation compatibility between fiber and soil, collapse mechanic model was simplified and collapse simulation experiment system was designed.

During the formation of soil voids, the friction imposed on optical fiber at the edge of void and its influence area are changeable. Thus, optical fiber fixation should be considered in the model design (Liu et al., 2010; Yao et al., 2005). Intertwist, one of the fixation methods, is adopted which can express the way how friction varies with loads effectively (Figure 3). 


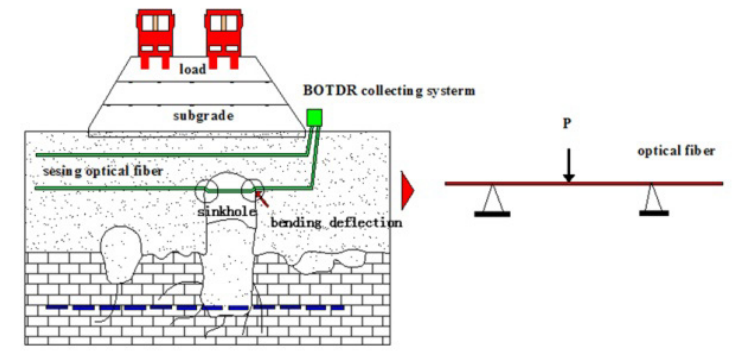

Figure 3. Simplified sinkhole model.

\section{Experiment system}

The displacement of optical fiber relative to soil varies with the load. This can be simulated by an experiment system which consists of a clamping wheel, adjustable supporter, dial indicator and vertical loading system. And the formation of soil voids with $0.5 \sim 2.5 \mathrm{~m}$ span under different loads can be simulated as well.

\section{Test and analysis}

Two types of experiments, variable load in certain distance and variable distance under certain load adopting ordination and GFRP optical fiber, were carried out, respectively.

AQ8603 Optical Fiber Strain Analyzer(BOTDR) produced by the ANDO corporation of Japan was used to measure the strain distribution in the optical fiber. The main index of the instrument is shown in Table 1.

\section{Test under stepwise variable load in certain distance}

The experiment simulates the load changes of the soil cave roof by loading and unloading on the optical fiber to analyze the changes of the axial strain and the optical fiber deformation.

\section{Experiment process}

Experiments were performed for Glassfiber Reinforced Plastic (GFRP) optical fiber and ordinary optical fiber respectively. The positions were recorded by the labels on it. For GFRP optical fiber, fixed segments were 920$923 \mathrm{~m}$ and $924.5-927.5 \mathrm{~m}$, and the loading point at $923.5 \mathrm{~m}$. For ordinary optical fiber, fixed segments by winding is $1065-1068 \mathrm{~m}$ and $1069.5-1072.5 \mathrm{~m}$, and the loading point at $1068.75 \mathrm{~m}$. The loading point deformation and strain in the sensing fiber were measured by dial indicator and AQ8603. The loading step follows $0 \mathrm{~kg}, 0.5 \mathrm{~kg}, 1 \mathrm{~kg}, 2 \mathrm{~kg}$, $3 \mathrm{~kg}$ and $5 \mathrm{~kg}$. Test data were recorded for every step loading and unloading.

\section{Test data processing and analysis}

According to its principle, the strain measured by the strain instrument is the integrated strain within $1 \mathrm{~m}$ starting from the monitoring point (Wu et al., 2005; Yue et al., 2007). Taking the value got from connectivity test as the initial value of optical fiber, strain change is the difference between the loading test value and the initial value.

According to the strain change distribution as shown in Figures 4 and 5, under the same load the strain influence zoon of the GFRP optical fiber is smaller than that of the ordinary optical fiber. With increasing loading, the strain influence zoon (distance) becomes more significant for GFRP fiber. Due to the small friction coefficient between GFRP fiber and wound case, the friction length must be increased to obtain the enough friction. The strain change of ordinary fiber is larger than that for the GFRP fiber under the same loading conditions, which indicates that the ordinary optical fiber is more sensitive to load comparing with the GFRP fiber. In other words, the ordinary optical fiber can serve low loading very well. It

Table 1. AQ8603(BOTDR)Technical Index.

\begin{tabular}{|c|c|c|c|c|c|c|}
\hline \multicolumn{2}{|l|}{ Technical Index } & \multicolumn{5}{|c|}{ Optional parameter } \\
\hline \multicolumn{2}{|l|}{ Measure distance } & \multicolumn{5}{|c|}{$1,2,5,10,20,40,80 \mathrm{~km}$} \\
\hline \multicolumn{2}{|l|}{ Pulse width } & $10 \mathrm{~ns}$ & $20 \mathrm{~ns}$ & $50 \mathrm{~ns}$ & $100 \mathrm{~ns}$ & $200 \mathrm{~ns}$ \\
\hline \multirow[t]{2}{*}{ Dynamic range } & $\pm 0.004 \%(2 \mathrm{~s})$ & $2 \mathrm{~dB}$ & $6 \mathrm{~dB}$ & $10 \mathrm{~dB}$ & $13 \mathrm{~dB}$ & $15 \mathrm{~dB}$ \\
\hline & $\pm 0.003 \%(2 \mathrm{~s})$ & - & - & $8 \mathrm{~dB}$ & $11 \mathrm{~dB}$ & $13 \mathrm{~dB}$ \\
\hline \multicolumn{2}{|c|}{ Length resolution } & $1 \mathrm{~m}$ & $2 \mathrm{~m}$ & $5 \mathrm{~m}$ & $11 \mathrm{~m}$ & $22 \mathrm{~m}$ \\
\hline \multicolumn{2}{|c|}{ Strain test accuracy } & \multicolumn{2}{|c|}{$\begin{array}{c} \pm 0.004 \%(2 \mathrm{~s}) \\
( \pm 0.01 \%)\end{array}$} & \multicolumn{3}{|c|}{$\begin{array}{c} \pm 0.003 \%(2 \mathrm{~s}) \\
( \pm 0.005 \%)\end{array}$} \\
\hline \multicolumn{2}{|c|}{ Strain test repeatability } & $<0.04 \%$ & \multicolumn{4}{|c|}{$<0.02 \%$} \\
\hline
\end{tabular}

In the experiment, $\pm 0.004 \%(2 \mathrm{~s})$ strain, $10 \mathrm{~cm}$ sampling distance and $1 \mathrm{~m}$ length resolution were adopted. Fiber connectivity was tested before the experiment. 


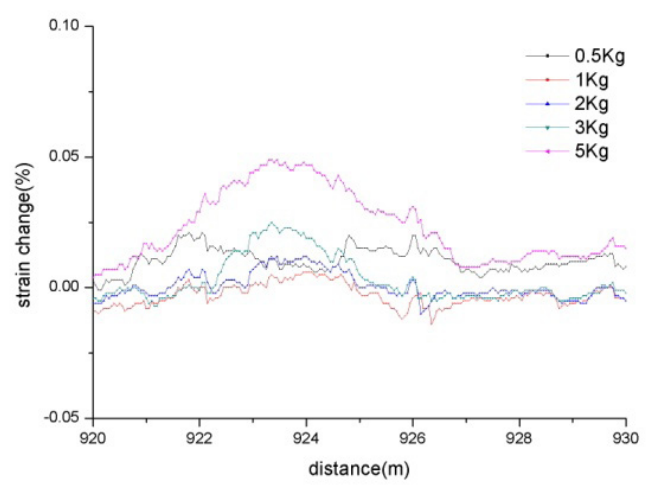

Figure 4. The loading point strain change (GFRP).

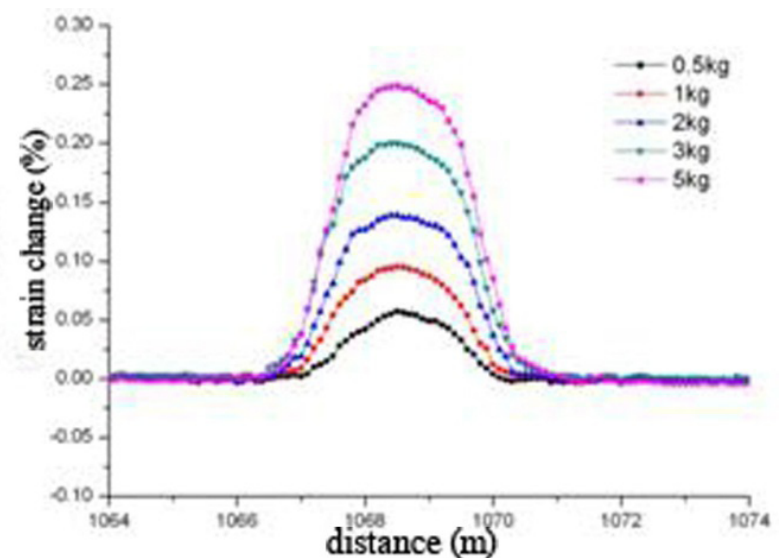

Figure 5. The loading point strain change (Ordinary optical fiber).

is suitable to be used for the soil bearing low pressure or having a low cohesion with the fiber.

When the stratum which the optical fiber is buried in lost cohesiveness, the sensing optical fiber was gradually unloaded. Following the soil void overburden collapse, the optical fiber was finally separated from surrounding soil mass this process can be simulated by unloading experiment (Figures 6 and 7). Unloading experiment demonstrates that the sensing optical fiber can respond to the deformation of sinkhole collapse, and the position of the coverboard loading and the optical fiber axial strain has good relationship. The overburden stratum thickness of an incipient sinkhole, the friction between the soil and optical fiber, and the cohesion of soil mass must be considered when choosing optical fiber. Therefore, the correct optical fiber must be selected in order to avoid the elastic modulus value exceeding the test range.

Test under variable distance in certain load This experiment simulated the sensing optical fiber axial strain changes in different spans of the sinkhole by applying certain load.

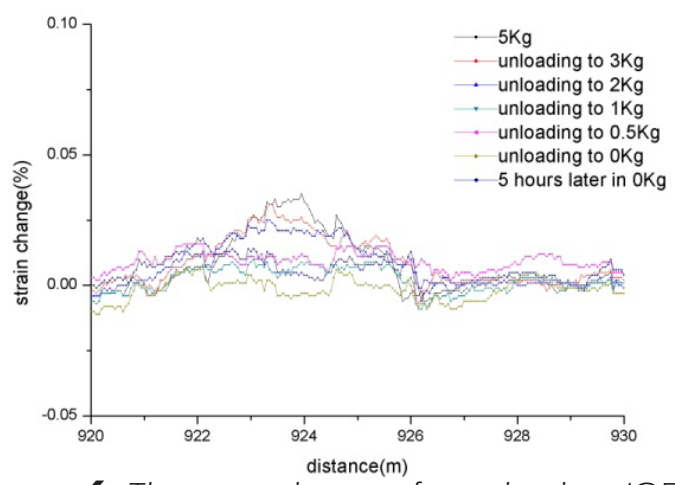

Figure 6. The strain change after unloading (GFRP).

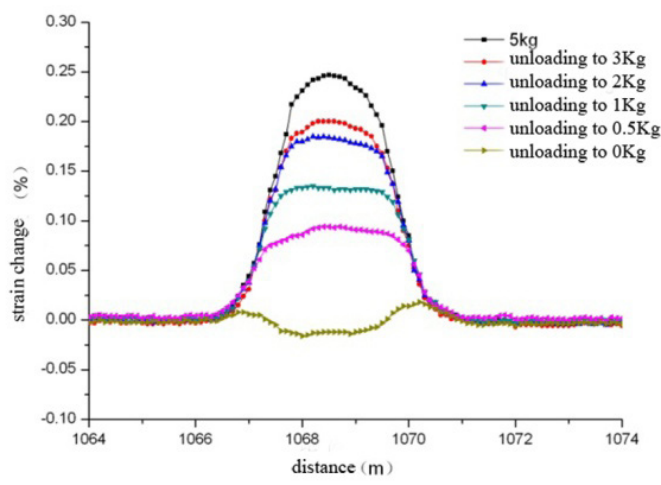

Figure 7. The strain change after unloading (Ordinary optical fiber).

The experiment process

The load are applied $2 \mathrm{Kg}$ on the ordinary optical fiber and $5 \mathrm{Kg}$ on the GFRP optical fiber respectively The experiment simulates the sinkhole span starting from 1 meter to 2.5 meter with $0.5 \mathrm{~m}$ interval.

Test data processing and analysis

In order to analyze the change of the sensing optical fiber strain, there is a mechanical analysis about the certain load experiment (Figure 8).

$$
2 \mathrm{~T} \sin \theta=\mathrm{G}
$$

where:

$\mathrm{L}$ - the distance of the fixed point;

$\Delta \mathrm{h}$-the vertical displacement of the loading point;

G-load;

T-the sensing optical fiber axial stretching force;

$\Theta$ - the included angle between the sensing optical fiber and the level. 
According to Figure 9, the maximal vertical displacement of the loading point is $55 \mathrm{~mm}$ and the minimum distance of the fixed point is $1000 \mathrm{~mm}$. under the assumption of small deformation, the hypotenuse is approximately equal to half of the distance of the fixed point, so, the $\sin \theta$ value is 0.11 and the $\theta$ value is 6.30 . The hypothesis $\theta$ equal to $\sin \theta$ can be established when the $\sin \theta$ is small enough.

$$
\mathrm{T}=\frac{\mathrm{G}}{2 \theta}
$$

Not considering the material factor, the relationship between sensing optical fiber axial stretching force and the included angle is inverse proportion. For ordinary optical fiber, the strain changes from $4.5 \mathrm{~m}$ to $5.4 \mathrm{~m}$, corresponding to the fixed point distance changing from $1 \mathrm{~m}$ to $2.5 \mathrm{~m}$ (Figure 10 ).

For the GFRP optical fiber (Figure 11), analysis of the optical fiber elastic modulus and the friction between the optical fiber and the soil shows that the distance of the fixed point corresponds to the strain change. According to the analysis ,the ordinary optical fiber elastic modulus

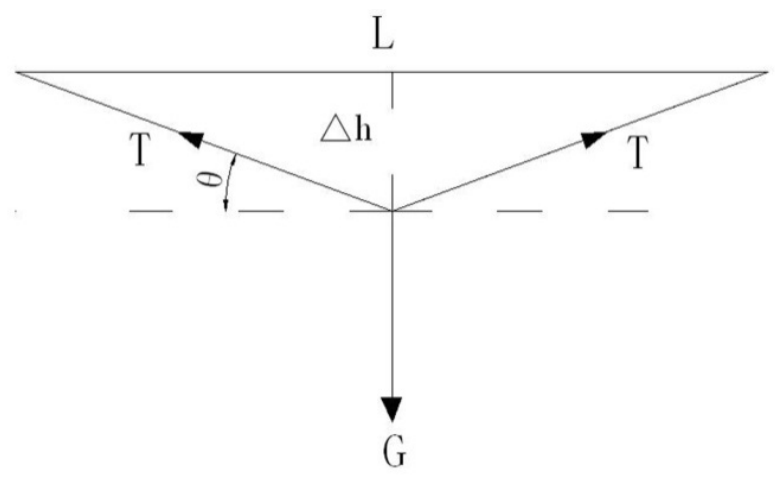

Figure 8. Loading section stress analysis

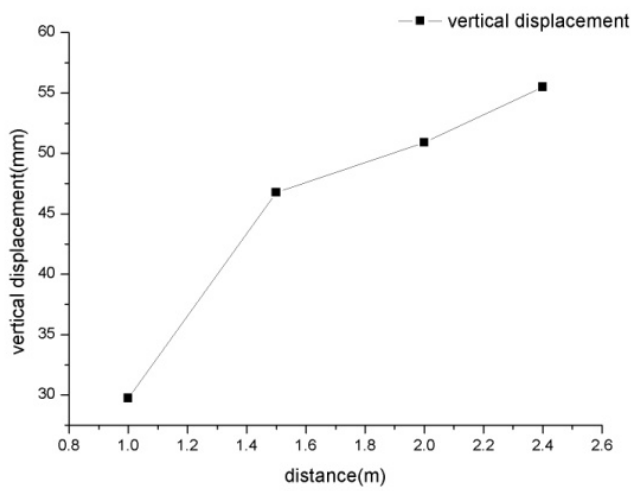

Figure 9. Vertical displacement in different sinkhole span.

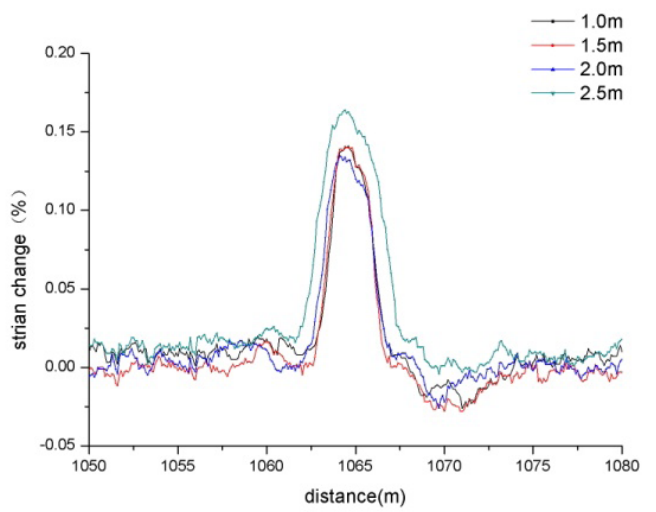

Figure 10. Strain change in different sinkhole span (Ordinary optical fiber).

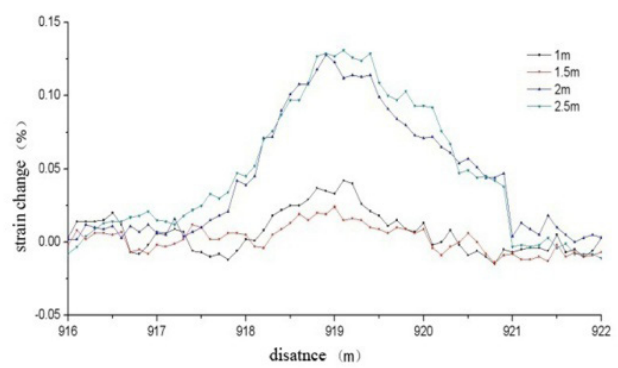

Figure 11. Strain change in different sinkhole span (GFRP).

is smaller and the friction is bigger than the GFRP optical fiber, so, its strain change scope is bigger. The change of the sinkhole deformation can be identified in the image by analyzing the optical fiber material characteristics and the load.

\section{Conclusion}

In the process of soil void formation and subsequent sinkhole collapse, axial strain and deformation of the optical fiber have good correspondence to the load variation. It is feasible to adopt the fiber-optical sensing technology to monitor the location, size and collapsing process of the void in soil.

Under a certain load, fiber strain corresponds to the size of soil void, but different fiber materials have specific effects on the strain value, which must be understand and choose appropriately.

Thus, the appropriate type of optical fiber or improving the deformation coordination between the soil and the fiber by indirect measurement, will strengthen the response sensitivity. 
Although the modeling test was carried out on a simplified model, it still demonstrates that the strain characteristics of the optical fiber due to soil void deformation may be a useful tool for predicting sinkhole collapse.

\section{References}

Chen G. Karst collapse of ground soil genesis, prevention and remediation. Beijing (China): Railway Publishing House.

Jiang X, Lei M, Chen Y, Ge J. 2006. An experiment study of monitoring sinkhole collapse by using BOTDR optical fiber sensing technique. Hydrogeology \& Engineering Geology 6: 75-80.

Li K, Shi B, Tang C, et al. 2010. Feasibility research on soil deformation monitoring with distributed optical fiber sensing technique. Rock and Soil Mechanics 31(6): 1781-1785.

Li Y, Zhu P, Lei M, et al. 2005. Monitoring technique and methods of the karst collapses. Carsologica Sinica 24(2): 103-108.

Liu J, Shi B, Zhang D, et al. 2006. Experimental study of foundation pit monitoring using BOTDR-based on distributed optical fiber sensor. Rock and Soil Mechanics 27(7): 1224-1228.

Liu Y, Sun H, Shang Y, et al. 2010. Study on the fixation technique of fiber based on BOTDR. Chinese Journal of Sensors and Actuators 23(09): 1353-1358.

Meng Y, Guan Z. 2011. A discussion on the key technical problem in monitoring and predicting sinkhole with optical fiber sensing (BOTDR) technique. Carsologica Sinica 30(2): 187-192.

Shi B, Xu X, Wang D, et al. 2005. Study on BOTDR-based distributed optical fiber strain measurement for tunnel health diagnosis. China Journal of Rock Mechanics and Engineering 24(15): 2622-2628.

Tang T, Zhu Y, CAI D, et al. 2006. Experimental research and rock sliding monitor of optical fiber sensing. Chinese Journal of Rock Mechanics and Engineering 25(2): 340-344.

Wu Z, Shi B, Harada T, et al. 2005. An experimental study on the measuring characteristics of BOTDR for structure health monitoring. China Civil Engineering Journal 38(8): 56-73.

Yao J, et al. 2005. Optical fiber principle and technology. Beijing (China): Science Press 5.

Yu X. 2006. Research on the testing of piles based on distributed optical fiber monitoring sensing technique. Electric Power Survey \& Design 06: 12-16.

Yue H, Dai Z, Liu Y, et al. 2007. Development of BOTDR distributed optical fiber sensor. Laser Journal 28(4): 4-5.
Zhang D, Shi B, Wu Z, et al. 2003. Distributed optical fiber sensor based on BOTDR and its application to structure health monitoring. China Civil Engineering Journal 36(11): 83-87. 
78 NCKRI SYMPOSIUM 2 I3TH SINKHOLE CONFERENCE 